\title{
Scanning laser ophthalmoscopy of the optic nerve head in exfoliation glaucoma and ocular hypertension with exfoliation syndrome
}

\author{
Mika Harju, Eija Vesti
}

\begin{abstract}
Aims-To study the relation between optic nerve head topography (Heidelberg retina tomograph, HRT) and disc area, visual field index mean defect (MD), and intraocular pressure (IOP), and to see whether change in HRT parameters is associated with change in $M D$ in a prospective follow up.

Methods -80 consecutive patients (69 patients with exfoliation glaucoma and 11 with ocular hypertension combined with exfoliation syndrome) were examined before IOP reducing intervention and prospectively followed every 6 months for 2 years.

Results-At the entry point, multiple regression analysis showed significant linear association between MD and all HRT parameters, when controlling for disc area. Disc area showed significant association with cup area, cup/disc area ratio, rim area, cup volume, and mean RNFL thickness. Six months after intervention IOP had decreased significantly. Reversible changes in cup area, cup/disc area ratio, rim area, cup volume, rim volume, mean cup depth, and maximum cup depth were associated with decrease in IOP. During the follow up period from 6 month to 2 years, IOP did not change significantly, and $M D$ was used as a measure of progression of glaucoma. During this period, only cup shape measure among HRT parameters showed significant association with subsequent change in MD. Conclusion-Disc area should be taken into account when using HRT to compare patients. Any effect of change in IOP should be also taken into account when using HRT in follow up. Cup shape measure is a promising indicator of progression of glaucomatous damage.

(Br f Ophthalmol 2001;85:297-303)
\end{abstract}

Helsinki University Eye Hospital, PO Box 220, FIN-00029 HYKS, Finland

M Harju

E Vesti

Correspondence to Dr Mika Harju

mika.harju@hueh.fi

Accepted for publication 4 October 2000
Evaluation of optic nerve head (ONH) topography is an essential part of glaucoma diagnosis. Nowadays, many new objective methods are available to aid in detection of $\mathrm{ONH}$ damage. Scanning laser ophthalmoscopy (SLO) allows acquisition of reproducible and reliable images of the $\mathrm{ONH}^{1-3}$ Many studies have examined the capability of SLO to differentiate between healthy eyes and eyes with ocular hypertension (OHT) and glaucoma. ${ }^{4-11} \mathrm{Al}-$ though the characteristics of glaucomatous damage of the $\mathrm{ONH}$ have been well documented, ${ }^{12}$ the $\mathrm{ONH}$ topography is highly individual making classification between healthy and glaucomatous eyes difficult. The most advantageous application of SLO would be its use in follow up of patients to detect change or progression in $\mathrm{ONH}$ topography.

In this prospective study, patients with exfoliation glaucoma (ExG) or OHT with exfoliation syndrome (ExOHT) were followed for 2 years. The aim was to examine whether the Heidelberg retina tomograph (HRT, Heidelberg Engineering $\mathrm{GmbH}$, Heidelberg, Germany) parameters depend on disc size and intraocular pressure (IOP), how the HRT parameters correlate with the visual field (VF) indices, and to see whether changes in the HRT parameters correlate with changes in VF indices

Patients and methods

All consecutive patients who were referred to the Helsinki University Eye Hospital between May 1995 and May 1997 because of ExOHT or uncontrolled ExG were included in the study. Further treatment of each patient was decided by a senior ophthalmologist who examined the patients and chose one of the following interventions: medical treatment, argon laser trabeculoplasty (ALT), or trabeculectomy. Patients with previous ALT were accepted in the study only if the senior ophthalmologist chose trabeculectomy as the further treatment. Otherwise patients who had undergone ALT, trabeculectomy, or cyclodestruction were excluded from the study. Only eyes with refraction errors from -5.0 to +5.0 dioptres were accepted in the study. Eyes with dense cataract making SLO imaging impossible were excluded.

A total of 80 patients, 31 men and 49 women ( $\mathrm{p}<0.05, \chi^{2}$ test), met the criteria. Mean age was 68 (SD 7) years, range 50-83 (Table 1). Only one eye per patient was included in the study. The eye with OHT or uncontrolled glaucoma was chosen. In bilateral cases, the right eye was chosen. Mean IOP was calculated from diurnal measurements of IOP at 7.30, 11.30 , and 14.30. Glaucoma was graded in seven stages according to a system modified from that of Thorburn ${ }^{13}$ (Table 2). The intervention was a change in the topical glaucoma medication in 13 eyes, ALT in 42 eyes, and trabeculectomy in 25 . Of the 25 eyes in the trabeculectomy group, 11 had previously been treated with ALT. One eye had recovered from a venous occlusion (no VF defect at study 
Table 1 Demographic data for patients at the start of the study

\begin{tabular}{lll}
\hline & Mean (SD) & Range \\
\hline Mean age (years) & $68.0(7.0)$ & $50-83$ \\
Mean diurnal IOP (mm Hg) & $24.2(6.1)$ & $12.3-50.0$ \\
IOP after HRT (mm Hg) & $28.3(9.1)$ & $12.0-55.0$ \\
Mean refractive error (dioptres) & $0.70(1.90)$ & $-4.75-4.50$ \\
\hline & Eyes & $\%$ \\
\hline Visual acuity, Snellen lines & & \\
$\geqslant 0.8$ & 53 & 66.2 \\
$0.4-0.7$ & 23 & 28.8 \\
$\leq 0.3$ & 4 & 5.0 \\
Staging of glaucoma & 11 & 13.8 \\
$1=$ OHT & 23 & 28.7 \\
2 & 26 & 32.5 \\
3 & 13 & 16.3 \\
4 & 4 & 5.0 \\
5 & 2 & 2.5 \\
6 & 1 & 1.3 \\
7 & & \\
Other eye disease & & 1.3 \\
Senile macular degeneration & 1 & 1.3 \\
Pigment epithelium atrophy & 1 & 6.3 \\
Suspicion of macular hole & 5 & 1.3 \\
Macular drusen & 1 & 1.3 \\
Venous occlusion & 1 & \\
Non-proliferative diabetic retinopathy & & \\
\hline
\end{tabular}

Table 2 Staging of glaucoma. Modified from Thorburn ${ }^{13}$

$\begin{array}{ll}\text { Stage 1: } & \begin{array}{l}\text { OHT = elevated IOP exceeding } 24 \mathrm{~mm} \mathrm{Hg} \text { on at least two occasions, or one } \\ \text { single measurement of } 30 \mathrm{~mm} \text { Hg or more with a normal visual field and without } \\ \text { glaucomatous cupping of the optic disc. }\end{array} \\ \text { Stage 2: } & \begin{array}{l}\text { Glaucomatous disc cupping with normal visual field. } \\ \text { Glaucomatous disc cupping and one scotoma within } 30^{\circ} \text {, and/or a nasal step or } \\ \text { sector shaped defect in the periphery. }\end{array} \\ \text { Stage 3: } & \begin{array}{l}\text { As in stage 3, but with the addition of a new scotoma within } 30^{\circ} \text { in the opposite } \\ \text { half of the visual field, or the creation of a breakthrough to the periphery. } \\ \text { As in stage 4, with the addition of a breakthrough to the periphery both upwards } \\ \text { and downwards from the paracentral scotoma. }\end{array} \\ \text { Stage 5: } & \text { A small remnant of the central visual field plus a temporal remnant. } \\ \text { Stage 6: } & \text { A temporal remnant, loss of central visual field (visual acuity } 0.1 \text { or less). }\end{array}$

entry) and one eye had a stable nonproliferative diabetic retinopathy with only few microaneurysms in the mid-periphery. Seven eyes had some signs of senile macular degeneration: one eye had atrophy of the pigment epithelium and was excluded in analysis of VF indices, one eye with a suspicion of a macular hole (visual acuity 1.0), and five eyes with macular drusen had no central or paracentral VF defects and were not excluded.

Patients were followed prospectively and examined every 6 months, with analyses made at 6 months and 2 years. Examinations included stereophotography and SLO imaging of the $\mathrm{ONH}$, perimetry, diurnal measurement of IOP, measurement of visual acuity, and biomicroscopic examination. VFs were taken with the остоPUs perimeter program G1, and only fields with less than $25 \%$ false negative and false positive answers were accepted in the analyses. If the patient was unable to perform reliable automated perimetry, Goldmann kinetic perimetry was performed. Pupils were dilated with tropicamide and phenylephrine eye drops before SLO imaging. IOP was also measured right after imaging.

SLO imaging was performed with the HRT, the reproducibilty and details of which have been reported elsewhere. ${ }^{1-3}$ Briefly, a $670 \mathrm{~nm}$ diode laser scans the retina using a 10,15 , or 20 degree field. In 1.6 seconds, a series of 32 two dimensional images in 32 focal planes with $256 \times 256$ pixel resolution are acquired. A topographic image representing the surface height in every pixel is created by the software (version 2.01). The operator draws a contour line at the inner border of the scleral ring, and stereometric variables are created by the software. Keratometry values were used for correction of magnification errors, and it was repeated after surgery in eyes operated on. Three topographic images using the $10^{\circ} \times 10^{\circ}$ field and approved by the internal quality program of the software were obtained. The mean image used in our analyses was created from three single images. All contour lines were drawn by the same operator $(\mathrm{MH})$, and the contour line of the baseline image was exported to follow up images. Stereophotographs of the $\mathrm{ONH}$ were used to aid in drawing of the inner border of the scleral ring.

The study followed the tenets of the Declaration of Helsinki and was approved by the department of ophthalmology ethics committee. Informed consent was obtained from all patients before testing.

Statistical analyses were performed with the SPSS software package (version SPSS 8.0 for Windows, SPSS Inc, Chicago, IL, USA). Normality was tested with the one sample Kolmogorov-Smirnov test. A paired $t$ test and the Wilcoxon signed rank test served for pairwise comparisons. Multiple linear regression analyses were performed with the enter and stepwise procedures. The residuals were tested and found to be normally distributed, homeoscedastic, and non-biased.

\section{Results}

CHANGES IN IOP AND VISUAL FIELD INDICES

Table 3 shows the mean values for IOPs and $\mathrm{VF}$ indices before intervention and at the 6 month and 2 year follow up visits. Decrease in mean IOP of the diurnal curve and decrease in IOP measured after HRT were statistically significant. Of the VF indices, the mean defect (MD) had decreased significantly at all follow up visits compared to pre-intervention values.

Table 3 IOP and visual field indices before intervention and at follow up visits

\begin{tabular}{|c|c|c|c|c|c|}
\hline & Preintervention & 6 months & \multirow[b]{2}{*}{ p Value } & \multirow{2}{*}{$\begin{array}{l}2 \text { years } \\
\text { Mean }(S D)\end{array}$} & \multirow[b]{2}{*}{$p$ Value } \\
\hline & Mean (SD) & Mean $(S D)$ & & & \\
\hline Mean diurnal IOP $(\mathrm{mm} \mathrm{Hg})$ & $24.4(6.1)$ & $16.2(3.9)$ & $<0.001 \dagger$ & $17.7(3.2)$ & $<0.001 \dagger$ \\
\hline IOP after HRT (mm Hg) & $28.2(9.0)$ & $17.7(6.1)$ & $<0.001 \dagger$ & $19.2(5.0)$ & $<0.001 t$ \\
\hline $\operatorname{MS}(\mathrm{dB})^{\star}$ & $17.9(6.5)$ & $18.6(5.9)$ & $0.022 \dagger$ & $19.3(5.8)$ & $0.011 \dagger$ \\
\hline$M D(d B)^{\star}$ & $8.6(6.6)$ & $7.7(5.9)$ & $0.020 \dagger$ & $7.1(5.8)$ & $0.003 \dagger$ \\
\hline $\mathrm{LV}(\mathrm{dB})^{\star}$ & $26.4(24.0)$ & $29.6(28.4)$ & 0.750 & $27.2(27.2)$ & 0.954 \\
\hline
\end{tabular}

$\star$ Tested with Wilcoxon signed rank test, the others with paired $t$ test.

†Significant at the 0.05 level. 
Table 4 The results of multiple linear regression analysis showing the associations between HRT parameters and the MD and disc area

\begin{tabular}{|c|c|c|c|c|c|}
\hline Dependent variable & $R$ square & Anova p value & $\begin{array}{l}\text { Explanatory } \\
\text { variable }\end{array}$ & $B$ & $p$ value \\
\hline \multirow[t]{2}{*}{ Cup area } & 0.65 & $<0.001 \dagger$ & MD & 0.030 & $<0.001 \dagger$ \\
\hline & & & Disc area & 0.787 & $<0.001 \dagger$ \\
\hline \multirow{2}{*}{ Cup/disc area ratio } & 0.32 & $<0.001 \dagger$ & MD & 0.013 & $<0.001 \dagger$ \\
\hline & & & Disc area & 0.119 & $0.006 \dagger$ \\
\hline \multirow{2}{*}{ Rim area } & 0.26 & $<0.001 \dagger$ & $\mathrm{MD}$ & -0.030 & $<0.001 \dagger$ \\
\hline & & & Disc area & 0.213 & $0.018 \dagger$ \\
\hline \multirow{2}{*}{ Height variation contour } & 0.24 & $<0.001 \dagger$ & $\mathrm{MD}$ & -0.006 & $0.001 \dagger$ \\
\hline & & & Disc area & -0.041 & $0.065^{\star}$ \\
\hline \multirow[t]{2}{*}{ Cup volume } & 0.53 & $<0.001 \dagger$ & $\mathrm{MD}$ & 0.024 & $<0.001 \dagger$ \\
\hline & & & Disc area & 0.294 & $<0.001 \dagger$ \\
\hline \multirow[t]{2}{*}{ Rim volume } & 0.21 & $<0.001 \dagger$ & $\mathrm{MD}$ & -0.010 & $<0.001 \dagger$ \\
\hline & & & Disc area & 0.006 & 0.861 \\
\hline \multirow[t]{2}{*}{ Mean cup depth } & 0.28 & $<0.001 \dagger$ & $\mathrm{MD}$ & 0.010 & $<0.001 \dagger$ \\
\hline & & & Disc area & 0.045 & 0.130 \\
\hline \multirow{2}{*}{ Maximum cup depth } & 0.17 & $0.002 \dagger$ & $\mathrm{MD}$ & 0.011 & $0.001 \dagger$ \\
\hline & & & Disc area & 0.047 & 0.317 \\
\hline \multirow[t]{2}{*}{ Cup shape measure } & 0.26 & $<0.001 \dagger$ & $\mathrm{MD}$ & 0.006 & $<0.001 \dagger$ \\
\hline & & & Disc area & 0.042 & $0.052^{\star}$ \\
\hline \multirow[t]{2}{*}{ Mean RNFL thickness } & 0.26 & $<0.001 \dagger$ & $\mathrm{MD}$ & -0.004 & $<0.001 \dagger$ \\
\hline & & & Disc area & -0.029 & $0.042 \dagger$ \\
\hline \multirow[t]{2}{*}{ RNFL cross section area } & 0.20 & $<0.001 \dagger$ & $\mathrm{MD}$ & -0.021 & $<0.001 \dagger$ \\
\hline & & & Disc area & 0.040 & 0.561 \\
\hline
\end{tabular}

†Significant at 0.05 level.

$\star$ Borderline significance.

ASSOCIATIONS BETWEEN HRT PARAMETERS AND

VISUAL FIELD INDICES AT BASELINE

Associations between HRT parameters, MD, and disc area were studied by multiple regression analyses with the enter procedure. Analysis was repeated separately for every HRT parameter with disc area and MD as explanatory variables (Table 4 ). The $\mathrm{R}$ square shows how much of the variation in the dependent variable could be explained by the model including the two explanatory variables. Column B shows partial regression coefficients. According to the analyses, MD together with disc area could explain $65 \%$ of the variation in cup area. The analysis also shows that one unit increase in MD $(\mathrm{dB})$ was associated with 0.030 units $\left(\mathrm{mm}^{2}\right)$ increase in cup area $(\mathrm{p}$ $<0.001$ ) when the optic disc area was taken into account. Subsequently, in eyes with one unit $\left(\mathrm{mm}^{2}\right)$ larger discs, cup area tends to be 0.787 units $\left(\mathrm{mm}^{2}\right)$ larger $(\mathrm{p}<0.001)$ when the effect of glaucomatous damage (measured with MD) was taken into account. Similar statistically significant linear associations existed between MD and the other HRT parameters, as well. The optic disc area showed significant association with cup area, cup/disc area ratio, rim area, cup volume, and mean retinal nerve fibre layer (RNFL) thickness. Associations with borderline significance were found between disc area and height variation contour and cup shape measure. Rim volume, mean cup depth, maximum cup depth, and RNFL cross section area appeared to be unaffected by the area of the $\mathrm{ONH}$.

REVERSAL CHANGES IN HRT

Associations between change in IOP and changes in the HRT parameters were similarly studied with multiple linear regression analyses. The period from the pre-intervention visit to the first follow up visit at 6 months was chosen, since the greatest change in IOP occurred during that time. Changes were calculated as "post-treatment value minus pretreatment value". A negative value indicates decrease in the variable and vice versa. Age, disc area, change in IOP (values measured after imaging with dilated pupils), and stage of glaucoma served as explanatory variables of the procedure. Each of the HRT parameters served separately as a dependent variable (Table 5). Column B shows the partial regression coefficients, with a positive prefix indicating that changes in dependent and the explanatory variables were in the same direction. Decrease in IOP was associated with a significant decrease in cup area, cup/disc area ratio, cup volume, mean cup depth, and maximum cup depth, and a significant increase in rim area and rim volume, when effects of age, stage of glaucoma, and disc area were taken into account. No association appeared between change in IOP and height variation contour, cup shape measure, mean RNFL thickness, or RNFL cross section area. Age had a significant association with changes in cup volume, mean cup depth, and maximum cup depth; in older patients, values for these variables decreased more than in younger patients. Stage of glaucoma had a significant association only with changes in cup volume and mean cup depth; these variables decreased more in eyes with advanced glaucoma than in eyes with early glaucoma. Disc area had a significant association only with change in cup volume and height variation contour; in larger discs, cup volume decreased and height variation contour increased more than in smaller discs.

FOLLOW UP FROM 6 MONTHS TO 2 YEARS

As shown above, decrease in IOP affected most of the HRT parameters. To reduce this effect of IOP on HRT parameters during the follow up period, a separate analysis of changes from 6 months to 2 years was performed, during which period the IOP was more stable. IOP, measured after imaging, increased from 16.8 (SD 3.8) $\mathrm{mm} \mathrm{Hg}$ at 6 months to 18.0 (4.5) $\mathrm{mm} \mathrm{Hg}$ at 2 years $(\mathrm{p}=0.052$, Wilcoxon signed rank test). MD was selected as an indicator of progression of glaucoma, and its change served 
Table 5 Results of multiple linear regression analysis, showing associations between changes in HRT from pre-intervention to 6 months with change in IOP (from pre-intervention to 6 months), age of patient, and stage of glaucoma

\begin{tabular}{|c|c|c|c|c|c|}
\hline Dependent variable (change in) & $R$ square & Anova p value & Explanatory variable & $B \times 10^{-3}$ & p Value \\
\hline \multirow{4}{*}{ Cup area } & 0.29 & $<0.001 \dagger$ & IOP change & 5.25 & $<0.001 \dagger$ \\
\hline & & & Disc area & -5.77 & 0.814 \\
\hline & & & Age & 2.22 & 0.164 \\
\hline & & & Stage of glaucoma & -4.52 & 0.678 \\
\hline \multirow[t]{4}{*}{ Cup/disc area ratio } & 0.26 & $<0.001 \dagger$ & IOP change & 2.16 & $<0.001 \dagger$ \\
\hline & & & Disc area & 1.39 & 0.902 \\
\hline & & & Age & 1.06 & 0.150 \\
\hline & & & Stage of glaucoma & -2.82 & 0.573 \\
\hline \multirow[t]{4}{*}{ Rim area } & 0.26 & $<0.001 \dagger$ & IOP change & -4.50 & $<0.001 \dagger$ \\
\hline & & & Disc area & 2.96 & 0.900 \\
\hline & & & Age & -2.54 & 0.098 \\
\hline & & & Stage of glaucoma & 1.83 & 0.861 \\
\hline \multirow[t]{4}{*}{ Height variation contour } & 0.22 & $0.002 \dagger$ & IOP change & -1.02 & 0.085 \\
\hline & & & Disc area & 29.58 & $0.022 \dagger$ \\
\hline & & & Age & -1.54 & 0.063 \\
\hline & & & Stage of glaucoma & 7.51 & 0.184 \\
\hline \multirow[t]{4}{*}{ Cup volume } & 0.39 & $<0.001 \dagger$ & IOP change & 3.04 & $0.003+$ \\
\hline & & & Disc area & -42.87 & $0.046 \dagger$ \\
\hline & & & Age & 4.39 & $0.002 \dagger$ \\
\hline & & & Stage of glaucoma & -22.62 & $0.018 \dagger$ \\
\hline \multirow[t]{4}{*}{ Rim volume } & 0.16 & $0.016 \dagger$ & IOP change & -1.38 & $0.006 \dagger$ \\
\hline & & & Disc area & 11.78 & 0.272 \\
\hline & & & Age & -0.42 & 0.547 \\
\hline & & & Stage of glaucoma & 3.36 & 0.479 \\
\hline \multirow[t]{4}{*}{ Mean cup depth } & 0.35 & $<0.001 \dagger$ & IOP change & 1.24 & $0.007 \dagger$ \\
\hline & & & Disc area & 1.30 & 0.893 \\
\hline & & & Age & 1.61 & $0.001 \dagger$ \\
\hline & & & Stage of glaucoma & -13.94 & $0.002 \dagger$ \\
\hline \multirow[t]{4}{*}{ Maximum cup depth } & 0.24 & $0.001 \uparrow$ & IOP change & 2.33 & $0.008 \dagger$ \\
\hline & & & Disc area & -9.01 & $0.629^{\circ}$ \\
\hline & & & Age & 2.44 & $0.045 \dagger$ \\
\hline & & & Stage of glaucoma & -15.11 & 0.071 \\
\hline \multirow[t]{4}{*}{ Cup shape measure } & 0.06 & 0.332 & IOP change & 0.32 & 0.513 \\
\hline & & & Disc area & 10.54 & 0.319 \\
\hline & & & Age & 0.25 & 0.713 \\
\hline & & & Stage of glaucoma & -7.41 & 0.117 \\
\hline \multirow[t]{4}{*}{ Mean RNFL thickness } & 0.08 & 0.202 & IOP change & -0.51 & 0.154 \\
\hline & & & Disc area & 13.31 & 0.084 \\
\hline & & & Age & -0.44 & 0.376 \\
\hline & & & Stage of glaucoma & -1.42 & 0.675 \\
\hline \multirow{4}{*}{ RNFL cross section area } & 0.08 & 0.190 & IOP change & -2.66 & 0.141 \\
\hline & & & Disc area & 65.51 & 0.094 \\
\hline & & & Age & -2.551 & 0.319 \\
\hline & & & Stage of glaucoma & -7.70 & 0.655 \\
\hline
\end{tabular}

†Significant at the 0.05 level.

as the dependent variable in the analyses. Reliable VFs taken with Octopus G1 at 6 months and at 2 years were both available for only 56 eyes. Although the Wilcoxon signed rank test showed that the mean change in MD was nonsignificant (mean 6.9 (SD 4.9) dB at 6 months, $6.7(5.2) \mathrm{dB}$ at 2 years, $\mathrm{p}=0.487)$, a total of 31 eyes showed improvement in MD (range 0.10 $5.20 \mathrm{~dB}$ ) and 25 eyes impairment in $\mathrm{MD}$ (range 0.1-4.10 dB). Multiple linear regression analysis was performed to examine whether any of the HRT parameters were associated with change in MD. Mean IOP at 2 years (diurnal IOP), change in IOP from 6 months to 2 years (measured after imaging), age of patient at the first visit, and disc area were put into the model as a block with the entry procedure since they were known, according to previous analyses, to affect HRT parameters. Then a second block which included all HRT parameters (changes from 6 months to 2 years) was added to the model with the stepwise procedure. The only HRT parameter which was picked up with the stepwise procedure was change in cup shape measure. The final analysis with cup shape measure and the other factors (mean IOP, change in IOP, age, and disc area) was performed with the procedure, and resulted in a $\mathrm{R}$ square of $0.26(\mathrm{p}=0.008)$ and partial regression coefficients of $-4.13 \times$ $10^{-2}(\mathrm{p}=0.581)$ for mean IOP, $0.17(\mathrm{p}=$
$0.026)$ for change in IOP, $9.13(p=0.009)$ for age, $0.989(\mathrm{p}=0.051)$ for disc area, and 17.21 $(p=0.013)$ for cup shape measure. However, when examining the residual plots, three possible outliers where noted. The charts of these three patients were examined and they were the ones with the greatest decrease $(5.2 \mathrm{~dB})$ and the two with greatest increase (4.10 and $4.0 \mathrm{~dB}$ ) in MD during the follow up. The procedure was repeated with these three patients excluded, the results of which are shown in Table 6 . The model explained $25 \%$ of the change in MD from 6 months to 2 years. Increase in $\mathrm{MD}$ was associated with increase in cup shape measure $(p=0.046)$ and increase in IOP with borderline significance $(\mathrm{p}=0.056)$. Greater age affected MD in the same direction $(\mathrm{p}=0.033)$. In larger discs, $M D$ increased more $(p=0.010)$. IOP level at 2 years failed to show any significant effect on MD ( $p=0.997)$. The partial regression plot for change in cup shape measure and change in MD is shown in Figure 1.

The HRT parameters correlated with each other. These multiple correlations (multicollinearities) can result in inaccuracies in estimating the effects of HRT parameters; for example a HRT parameter can be taken into the model by chance. Therefore, the analysis was repeated with the enter procedure by taking each of the HRT parameters at one 
Table 6 Results of multiple linear regression analysis for changes from 6 months to 2 years, with associations between change in MD and explanatory variables

\begin{tabular}{llllll}
\hline $\begin{array}{l}\text { Dependent } \\
\text { variable }\end{array}$ & $R$ square & $\begin{array}{l}\text { Anovap } \\
\text { value }\end{array}$ & Explanatory variable & $B$ & p Value \\
\hline Change in MD & 0.25 & $0.015 \dagger$ & Mean IOP at 2 years & $-2.49 \times 10^{-2}$ & 0.581 \\
& & & Change in IOP & 0.127 & $0.056^{\star}$ \\
& & Age & $6.69 \times 10^{-2}$ & $0.033+$ \\
& & Disc area & 1.185 & $0.010 \dagger$ \\
& & Change in cup shape & 6.305 & $0.046 \dagger$ \\
& & measure & &
\end{tabular}

†Significant at the 0.05 level.

$\star$ Borderline significance.
Interestingly, rim volume, mean cup depth, maximum cup depth, and RNFL cross section area appeared to be unaffected by disc area, a fact supported by the findings of others concerning HRT in healthy eyes. ${ }^{8} 18$ Previously, the optic disc area has been shown to correlate with neuroretinal rim area, cup area, and cup/ disc ratio when measured from fundus photographs ${ }^{19-22}$ as well as with cup volume when measured by a different kind of computerised image analysis system (the Rodenstock analyser). ${ }^{23}$ Our result supports the importance of adjusting for disc area when HRT values are compared between different groups of patients.

After adjustment for optic disc area in multivariate analyses, MD was found to be associated with all HRT parameters. Correlations between VF indices and HRT parameters have also been reported, but those studies made no adjustment for optic disc area. ${ }^{24-28}$ Our findings suggest that all HRT parameters reflect glaucomatous damage when the effect of disc size is controlled for.

Experimental studies with enucleated human and primate eyes have shown that increase in IOP causes backward bowing of the lamina cribrosa. ${ }^{29}{ }^{30}$ In our study, reduction in IOP was associated with reversal changes in cup area, cup/disc area ratio, rim area, cup volume, rim volume, mean cup depth, and maximum cup depth. Previously, reversal of ONH topography after reduction in IOP has been documented in experimental and clinical studies with humans and primates using stereophotography or computerised image analysis. ${ }^{15} 16{ }^{31-35}$ At least four other studies have recently reported reversible changes documented with the HRT after reduction in IOP. ${ }^{36-39}$ Our findings accord best with those of Lesk et $a b^{37}$ who, when they correlated changes in HRT with percentage changes in IOP, found reversible changes 6 months after glaucoma surgery in the same parameters that we did. Irak et $a b^{36}$ evaluated percentage changes and mean changes in IOP, finding that percentage changes in IOP correlated also with changes in cup shape measure and RNFL cross section area, but not with changes in maximum cup depth; but no correlations existed between mean change in IOP and cup volume or rim volume. Topouzis et $a^{\beta 8}$ compared HRT parameters before and after trabeculectomy, but did not correlate the changes with IOP. Two weeks after treatment they reported reversible changes in some HRT parameters, but after 4 months only in cup shape measure, and at 8 months in no parameters. They suggest that lack of reversible changes might have been due to the advanced glaucoma of their patients. We included glaucoma stage in our analyses, and found it to be associated only with reversibility of cup volume and mean cup depth. In fact, reversible changes in these parameters were greater in the eyes with more advanced glaucoma. Reversible changes in advanced glaucoma has also been reported previously. $^{39}$

Age was associated with reversibility of cup volume, mean cup depth, and maximum cup depth. Older patients had greater reversible 
changes than younger ones, in accord with the findings of Lesk et $a l^{37}$ though their findings concerned only a subgroup of patients with IOP reduction of $40 \%$ or more.

To examine whether progression of glaucoma could be detected with HRT, we examined changes from 6 months to 2 years, a period selected because IOP remained stable, and most HRT parameters had been found to be affected by change in IOP. VF index MD was selected as the indicator of progression. It is not the ideal measure for progression, since it has been shown to be sensitive to cataract formation, long term fluctuation, and other physiological factors; however, it allows us to study any linear associations with indices of topography. Although only slight changes in the MD were noted during this period, change in cup shape measure in a positive direction, indicating "more glaucomatous", was associated with change in MD to higher values, and vice versa. No significant associations occurred with the other HRT parameters. This suggests that cup shape measure may be a sensitive indicator of progression in follow up, a theory supported by previous studies finding cup shape measure to be one of the best parameters to differentiate healthy eyes, eyes with OHT, and eyes with glaucoma ${ }^{4-6}{ }^{40}$ and to detect early glaucomatous VF loss. ${ }^{7}$ Cup shape measure has also been shown to correlate with VF indices. ${ }^{28}$ Recently, Kamal et $a l^{41}$ reported on changes in HRT parameters in 13 OHT patients who subsequently developed glaucoma. From the global HRT parameters, they found significant changes in cup area, cup/disc area ratio, and rim area, but not in cup shape measure (nor in cup volume or rim volume). However, they did not evaluate change in IOP during the follow up period, which might have had an effect on results.

We suggest that when using HRT to compare different groups of patients, the disc area should be taken into account, and in follow up of patients, any effect of change in IOP should also be taken into account. According to our results, cup shape measure is a promising indicator of progression of glaucomatous damage in the $\mathrm{ONH}$.

The authors thank Jukka Ollgren, MSc, for consultation on statistical analysis. Supported by the Finska Läkaresällskapet (Medical Society of Finland), Helsinki, Mary och Georg C Ehrnrooths Stiftelse, Helsinki, Liv och Hälsa, Helsinki, Silmäsäätiö (the Eye Foundation), Helsinki, De Blindas Vänner rf - Sokeain Ystävät ry, Helsinki, and the Clinical Research Institute Helsinki University Central Hospital, Helsinki.

1 Lusky M, Bosem ME, Weinreb RN. Reproducibility of optic nerve head topography measurements in eyes with undilated pupils. F Glaucoma 1993;2:104-9.

2 Mikelberg FS, Wijsman K, Schulzer M. Reproducibility of topographic parameters obtained with the Heidelberg retina tomograph. F Glaucoma 1993;2:101-3.

3 Rohrschneider K, Burk ROW, Kruse FE, et al. Reproducibility of the optic nerve head topography with a new laser tomographic scanning device. Ophthalmology 1994;101: 1044-9.

4 Uchida H, Brigatti L, Caprioli J. Detection of structural damage from glaucoma with confocal laser image analysis. Invest Ophthalmol Vis Sci 1996;37:2393-401.

5 Hatch WV, Flanagan JG, Etchells EE, et al. Laser scanning tomography of the optic nerve head in ocular hypertension tomography of the optic nerve head in ocular hyp

6 Bathija R, Zangwill L, Berry CC, et al. Detection of early glaucomatous structural damage with confocal scanning laser tomography. F Glaucoma 1998;7:121-7.
7 Mikelberg FS, Parfitt CM, Swindale NV, et al. Ability of the Heidelberg retina tomograph to detect early glaucomatous visual field loss. F Glaucoma 1995;4:242-7.

8 Wollstein G, Garway-Heath DF, Hitchings RA. Identification of early glaucoma cases with the scanning laser ophthalmoscope. Ophthalmology 1998;105:1557-63.

9 Zangwill LM, van Horn S, de Souza Lima M, et al. Optic nerve head topography in ocular hypertensive eyes using confocal scanning laser ophthalmoscopy. Am f Ophthalmol 1996;122:520-5.

10 Iester M, Broadway DC, Mikelberg FS, et al. A comparison of healthy, ocular hypertensive, and glaucomatous optic disc topographic parameters. F Glaucoma 1997;6:363-70.

11 Iester M, Mikelberg FS, Drance SM. The effect of optic disc size on diagnostic precision with the Heidelberg retina tomograph. Ophthalmology 1997;104:545-8.

12 Airaksinen PJ, Tuulonen A, Werner EB. Clinical evaluation of the optic disc and retinal nerve fiber layer. In: Ritch R, Shields MB, Krupin T, eds. The glaucomas. Basic sciences. 2nd ed. St Louis: Mosby-Year Book, 1996:617-57.

13 Thorburn W. The outcome of visual function in capsular glaucoma. Acta Ophthalmol (Copenh) 1988;66 (Suppl 184): 132-7.

14 Pohjanpelto P. Influence of exfoliation syndrome on prognosis in ocular hypertension greater than or equal to $25 \mathrm{~mm}$. A long-term follow-up. Acta Ophthalmol (Copenh) 1986;64:39-44

15 Katz LJ, Spaeth GL, Cantor LB, et al. Reversible optic disc cupping and visual field improvement in adults with glaucoma. Am f Ophthalmol 1989;107:485-92.

16 Tsai CS, Shin DH, Wan JY, et al. Visual field global indices in patients with reversal of glaucomatous cupping after intraocular pressure reduction. Ophthalmology 1991;98: 1412-9.

17 Heijl A, Bengtsson B. The effect of perimetric experience in patients with glaucoma. Arch Ophthalmol 1996;114:19-22.

18 Mardin CY, Horn FK. Influence of optic disc size on the sensitivity of the Heidelberg Retina Tomograph. Graefes Arch Clin Exp Ophthalmol 1998;236:641-5.

19 Bengtsson B. The variation and covariation of cup and disc diameters. Acta Ophthalmol (Copenh) 1976;54:804-18.

20 Jonas JB, Gusek GC, Naumann GO. Optic disc, cup and neuroretinal rim size, configuration and correlations in normal eyes. Invest Ophthalmol Vis Sci 1988;29:1151-8.

21 Britton RJ, Drance SM, Schulzer M, et al. The area of the neuroretinal rim of the optic nerve in normal eyes. $A m \mathcal{F}$ Ophthalmol 1987;103:497-504.

22 Garway-Heath DF, Ruben ST, Viswanathan A, et al. Vertical $\mathrm{cup} /$ disc ratio in relation to optic disc size: its value in the assessment of the glaucoma suspect. Br f Ophthalmol 1998; 82:1118-24.

23 Caprioli J, Miller JM. Optic disc rim area is related to disc size in normal subjects. Arch Ophthalmol 1987;105:1683-5.

24 Eid TM, Spaeth GL, Katz LJ, et al. Quantitative estimation of retinal nerve fiber layer height in glaucoma and the relationship with optic nerve head topography and visual field. f Glaucoma 1997;6:221-30.

25 Iester M, Mikelberg FS, Courtright P, et al. Correlation between the visual field indices and Heidelberg retina tomograph parameters. F Glaucoma 1997;6:78-82.

26 Tole DM, Edwards MP, Davey KG, et al. The correlation of the visual field with scanning laser ophthalmoscope measurements in glaucoma. Eye 1998;12:686-90.

27 Iester M, Swindale NV, Mikelberg FS. Sector-based analysis of optic nerve head shape parameters and visual field indices in healthy and glaucomatous eyes. F Glaucoma 1997;6: 371-6.

28 Brigatti L, Caprioli J. Correlation of visual field with scanning confocal laser optic disc measurements in glaucoma. Arch Ophthalmol 1995;113:1191-4.

29 Levy NS, Crapps EE, Bonney RC. Displacement of the optic nerve head. Response to acute intraocular pressure elevation in primate eyes. Arch Ophthalmol 1981;99:216674.

30 Levy NS, Crapps EE. Displacement of optic nerve head in esponse to short-term intraocular pressure elevation in human eyes. Arch Ophthalmol 1984;102:782-6.

31 Sogano S, Tomita G, Kitazawa Y. Changes in retinal nerve fiber layer thickness after reduction of intraocular pressure in chronic open-angle glaucoma. Ophthalmology 1993;100: 1253-8.

32 Chavis PS, Tomey KF, Al Rashed D, et al. Reversible optic nerve cupping with long-term intraocular pressure elevation. Glaucoma 1994;16:70-7.

33 Pederson JE, Herschler J. Reversal of glaucomatous cupping in adults. Arch Ophthalmol 1982;100:426-31.

34 Shirakashi $M$, Nanba K, Iwata K. Changes in reversal of cupping in experimental glaucoma. Longitudinal study. Ophthalmology 1992;99:1104-10.

35 Shin DH, Bielik M, Hong YJ, et al. Reversal of glaucomatous optic disc cupping in adult patients. Arch Ophthalmol 1989;107:1599-603.

36 Irak I, Zangwill L, Garden V, et al. Change in optic disk topography after trabeculectomy. Am f Ophthalmol 1996; 122:690-5.

37 Lesk MR, Spaeth GL, Azuara-Blanco A, et al. Reversal of optic disc cupping after glaucoma surgery analyzed with a scanning laser tomograph. Ophthalmology 1999;106:10138.

38 Topouzis F, Peng F, Kotas-Neumann R, et al. Longitudinal changes in optic disc topography of adult patients after trabeculectomy. Ophthalmology 1999;106:1147-51. 
39 Raitta C, Tomita G, Vesti E, et al. Optic disc topography before and after trabeculectomy in advanced glaucoma.

40 Iester M, Mikelberg FS, Swindale NV, et al. ROC analysis of Heidelberg retina tomograph optic disc shape measures in glaucoma. Can f Ophthalmol 1997;32:382-8.
41 Kamal DS, Viswanathan AC, Garway-Heath DF, et al. Detection of optic disc change with the Heidelberg retina tomograph before confirmed visual field change in ocular hypertensives converting to early glaucoma. Br F Ophthalmol 1999;83:290-4. 